\title{
Every Even Integer Greater than 500000 can be Expressed as a Sum of Two Odd Primes
}

\section{YinYue Sha}

Dongling Engineering Center, Ningbo Institute of Technology, Zhejiang University

Room 105, 9, TaoYuanXinCun, HengXi Town, NingBo, Z.J.315131, CHINA

shayinyue@qq.com

Received Date: July 04, $2017 \quad$ Accepted Date: July 18, $2017 \quad$ Published Date: July 25, 2017

Abstract: Every even integer greater than four can be expressed as a sum of two odd primes, and exists the formula as follows:

$\operatorname{Gp}(N) \geq \operatorname{INT}\left\{\operatorname{Kpc} \times\right.$ Ctwin $\left.\times N /(\operatorname{Ln} N)^{\wedge} 2\right\}-1 \geq \operatorname{INT}\left\{0.66016 \times N /(\operatorname{Ln} N)^{\wedge} 2\right\}^{\wedge} 1 \geq 1915>>1$

where the $\mathrm{Gp}(\mathrm{N})$ be the number of primes $\mathrm{P}$ with $\mathrm{N}-\mathrm{P}$ primes, or, equivalently, the $\mathrm{Gp}(\mathrm{N})$ be the number of ways of writing $\mathrm{N}$ as a sum of two primes, the $\mathrm{N}$ be the even integer greater than 500000 .

Keywords: Even integer, Goldbach prime, Goldbach's Conjecture.

One: The Proof Method of Goldbach's Conjecture

The Goldbach's Conjecture is one of the oldest unsolved problems in Number Theory. In its modern form, it states that every even integer greater than two can be expressed as a sum of two primes.

Let $\mathrm{N}$ be an even integer greater than 2 , and let $\mathrm{N}=(\mathrm{N}-\mathrm{Gp})+\mathrm{Gp}$, with $\mathrm{N}-\mathrm{Gp}$ and $\mathrm{Gp}$ prime numbers, the $\mathrm{Gp}\{\mathrm{Gp} \leq \mathrm{N} / 2\}$ be a Goldbach Prime of even integer N. Let $\mathrm{Gp}(\mathrm{N})$ be the number of Goldbach Primes of even integer N. The number of ways of writing $\mathrm{N}$ as a sum of two prime numbers, when the order of the two primes is important, is thus $\mathrm{GP}(\mathrm{N})=2 \mathrm{Gp}(\mathrm{N})$ when $\mathrm{N} / 2$ is not a prime and is $\mathrm{GP}(\mathrm{N})=2 \mathrm{Gp}(\mathrm{N})-1$ when $\mathrm{N} / 2$ is a prime. The Goldbach's Conjecture states that $\mathrm{Gp}(\mathrm{N})>0$, or, equivalently, that $\mathrm{GP}(\mathrm{N})>0$, for every even integer $\mathrm{N}$ greater than two.

We known that the Goldbach's Conjecture is true for every even integer N no greater than 30000 , therefore, we only need to prove that the Goldbach's Conjecture is true for every even integer N greater than 30000 , that is: $\mathrm{Gp}(\mathrm{N} \mid \mathrm{N}>30000) \geq 1$.

\section{Two: The Sieve Method About The Goldbach Primes}

Let $\mathrm{N}$ be an even integer greater than 30000 , then the even integer $\mathrm{N}$ can be expressed to the form as follows:

$\mathrm{N}=(\mathrm{N}-\mathrm{Gn})+\mathrm{Gn}, \mathrm{Gn} \leq \mathrm{N} / 2$

where $\mathrm{Gn}$ be the positive integer no greater than $\mathrm{N} / 2$.

\section{Sieve Method}

Let N-Gn and Gn are two positive integers, if $\mathrm{N}-\mathrm{Gn}$ and $\mathrm{Gn}$ any one can be divisible by the prime P, then sieves the positive integer $\mathrm{Gn}$; if both the $\mathrm{N}-\mathrm{Gp}$ and $\mathrm{Gp}$ can not be divisible by the all primes no greater than $\sqrt{\mathrm{N}}$, then both the N-Gp and Gp are primes at the same time, the prime Gp be called the Goldbach Prime of even integer $\mathrm{N}$.

\section{Theorem One}

Let $\mathrm{Pc}$ be an odd prime factor of even integer $\mathrm{N}$ and no greater than $\sqrt{\mathrm{N}}$, then the ratio of the number of integers Gp that both the N-Gp and Gp can not be divisible by the prime Pc to the total of integers Gn no greater than 
Every even integer greater than 500000 can be expressed as a sum of two odd primes

N/2 is follows:

$\mathrm{R}(\mathrm{N}, \mathrm{Pc})=\operatorname{INT}\{\mathrm{N} / 2-\mathrm{N} / 2 / \mathrm{Pc}\} /(\mathrm{N} / 2) /\{\operatorname{INT}(\mathrm{N} / 2)-\operatorname{INT}(\mathrm{N} / 2 / \mathrm{Pc})\} /(\mathrm{N} / 2)$

Proof

Because Pc is an odd prime factor of even integer N, therefore, both the N-Gn and Gn can or can not be divisible by prime Pc at the same time, then the number of integers Gn that the N-Gn and Gn any one can be divisible by the prime Pc is INT $\{(\mathrm{N} / 2) / \mathrm{Pc}\}$, the number of integers $\mathrm{Gn}$ that both the $\mathrm{N}-\mathrm{Gn}$ and $\mathrm{Gn}$ can not be divisible by the prime Pc is $\{\operatorname{INT}(\mathrm{N} / 2)-\operatorname{INT}(\mathrm{N} / 2 / \mathrm{Pc})\}=\operatorname{INT}\{\mathrm{N} / 2-\mathrm{N} / 2 / \mathrm{Pc}\}$, the ratio of the number of integers Gn that both the N-Gn and Gn can not be divisible by the prime Pc to the total of integers Gn no greater than N/2 is follows:

$\mathrm{R}(\mathrm{N}, \mathrm{Pc})=\{\operatorname{INT}(\mathrm{N} / 2)-\operatorname{INT}(\mathrm{N} / 2 / \mathrm{Pc})\} /(\mathrm{N} / 2)=\operatorname{INT}\{\mathrm{N} / 2-\mathrm{N} / 2 / \mathrm{Pc}\} /(\mathrm{N} / 2)$

\section{Theorem Two}

Let Pn be an odd prime no factor of even integer $N$ and no greater than $\sqrt{N}$, then the ratio of the number of integers $\mathrm{Gn}$ that both the N-Gn and Gn can not be divisible by the prime Pn to the total of integers Gn no greater than $\mathrm{N} / 2$ is follows:

$\mathrm{R}(\mathrm{N}, \mathrm{Pn})=\operatorname{INT}\{\mathrm{N} / 2-\mathrm{N} / \mathrm{Pn}\} /(\mathrm{N} / 2)=\{\operatorname{INT}(\mathrm{N} / 2)-\operatorname{INT}(\mathrm{N} / \mathrm{Pn})\} /(\mathrm{N} / 2)$

\section{Proof}

Because the Pn is an odd prime no factor of even integer $\mathrm{N}$, therefore, both the $\mathrm{N}-\mathrm{Gn}$ and $\mathrm{Gn}$ can not be divisible by the prime Pn at the same time, that is the N-Gn and Gn only one can be divisible or both the N-Gn and Gn can not be divisible by the prime Pn, then the number of integers Gn that the N-Gn and Gn any one can be divisible by the prime Pn is INT\{N/Pn\}, the number of integers Gn that both the N-Gn and Gn can not be divisible by the prime Pn is $\{\operatorname{INT}(\mathrm{N} / 2)-\operatorname{INT}(\mathrm{N} / \mathrm{Pn})\}=\operatorname{INT}\{\mathrm{N} / 2-\mathrm{N} / \mathrm{Pn}\}$, the ratio of the number of integers Gn that both the $\mathrm{N}-\mathrm{Gn}$ and Gn can not be divisible by the prime Pn to the total of integers Gn no greater than N/2 is follows:

$\mathrm{R}(\mathrm{N}, \mathrm{Pn})=\{\operatorname{INT}(\mathrm{N} / 2)-\operatorname{INT}(\mathrm{N} / \mathrm{Pn})\} /(\mathrm{N} / 2)=\operatorname{INT}\{\mathrm{N} / 2-\mathrm{N} / \mathrm{Pn}\} /(\mathrm{N} / 2)$

\section{Theorem Three}

The integer 2 is an even prime factor of even integer $\mathrm{N}$, the ratio of the number of integers Gn that both the N-Gn and Gn can not be divisible by the even prime 2 to the total of integers Gn no greater than N/2 is follows:

$\mathrm{R}(\mathrm{N}, 2)=\operatorname{INT}\{\mathrm{N} / 2-\mathrm{N} / 2 / 2\} /(\mathrm{N} / 2)=\{\operatorname{INT}(\mathrm{N} / 2)-\operatorname{INT}(\mathrm{N} / 2 / 2)\} /(\mathrm{N} / 2)$

Proof

Because the 2 is an even prime factor of even integer N, therefore, both the N-Gn and Gn can be divisible or can not be divisible by the even prime 2 at the same time, then the number of integers Gn that the N-Gn and Gn any one can be divisible by the even prime 2 is INT $\{\mathrm{N} / 2 / 2\}$, the number of integers $\mathrm{Gn}$ that both the N-Gn and Gn can not be divisible by the even prime 2 is $\{\operatorname{INT}(N / 2)-\operatorname{INT}(N / 2 / 2)\}=\operatorname{INT}\{N / 2-N / 2 / 2\}$, the ratio of the number of integers $\mathrm{Gn}$ that both the N-Gn and Gn can not be divisible by the even prime 2 to the total of integers Gn no greater than N/2 is follows:

$\mathrm{R}(\mathrm{N}, 2)=\{\operatorname{INT}(\mathrm{N} / 2)-\operatorname{INT}(\mathrm{N} / 2 / 2)\} /(\mathrm{N} / 2)=\operatorname{INT}\{\mathrm{N} / 2-\mathrm{N} / 2 / 2\} /(\mathrm{N} / 2)$

\section{Three: The Number of Goldbach Primes of Even InTEger}

Let $\mathrm{Gp}(\mathrm{N})$ be the number of Goldbach primes of even integer $\mathrm{N}$, let $\mathrm{Gp}(\mathrm{N}, \mathrm{Pn})$ be the number of Goldbach primes no greater than $\sqrt{\mathrm{N}}$, then exists the formulas as follows:

$\mathrm{Gp}(\mathrm{N})=\operatorname{INT}\left\{(\mathrm{N} / 2) \times \mathrm{R}(\mathrm{N}, 2) \times \prod \mathrm{R}(\mathrm{N}, \mathrm{Pci}) \times \prod \mathrm{R}(\mathrm{N}, \mathrm{Pni})\right\}+\mathrm{Gp}(\mathrm{N}, \mathrm{Pni})-1($ if $\mathrm{N}-1$ prime $)$ 
Every even integer greater than 500000 can be expressed as a sum of two odd primes

$=\operatorname{INT}\left\{(\mathrm{N} / 2) \times(1-1 / 2) \times \prod(1-1 / \mathrm{Pci}) \times \prod(1-2 / \mathrm{Pni})\right\}+\mathrm{Gp}(\mathrm{N}, \mathrm{Pni})-1($ if $\mathrm{N}-1$ prime $)$

Where Pci and Pni are odd primes no greater than $\sqrt{ } \mathrm{N}$.

Let $\mathrm{Pi}(\mathrm{N})$ be the number of primes less than an integer $\mathrm{N}$, then, be the formula as follows:

$\mathrm{Pi}(\mathrm{N}) \equiv \operatorname{INT}\{\mathrm{N} \times(1-1 / \mathrm{P} 1) \times(1-1 / \mathrm{P} 2) \times \ldots \times(1-1 / \mathrm{Pm})+\mathrm{m}-1\} \equiv \mathrm{P}(\mathrm{N})+\mathrm{Pi}(\sqrt{\mathrm{N}})-1$

$\operatorname{Pi}(\mathrm{N}) \approx \operatorname{Psha}(\mathrm{N}) \equiv \operatorname{Li}(\mathrm{N})-1 / 2 \times \operatorname{Li}\left(\mathrm{N}^{\wedge} 0.5\right)$

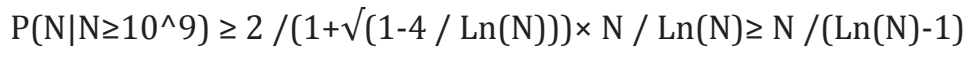

$\left.\mathrm{P}\left(\mathrm{N} \mid \mathrm{N} \geq 10^{\wedge} 4\right) \equiv \operatorname{INT}\{\mathrm{N} \times(1-1 / 2) \times \Pi(1) 1 / \mathrm{Pi})\right\} \geq \mathrm{N} / \mathrm{Ln}(\mathrm{N})$

Four: The Proof of Goldbach's Conjecture

Theorem Four

Every even integer greater than 500000 can be expressed as a sum of two odd primes.

Proof

According to the formula (5), we can obtain the formula as follows:

$\mathrm{Gp}(\mathrm{N})+1 \geq \operatorname{INT}\{(\mathrm{N} / 2) \times(1-1 / 2) \times \Pi(1-1 / \mathrm{Pci}) \times \Pi(1-2 / \mathrm{Pni})\}$

$=\operatorname{INT}\left\{(\mathrm{N} / 2) \times(1-1 / 2) \times \Pi((\mathrm{Pci}-1) /(\mathrm{Pci}-2)) \times \prod(1-2 / \mathrm{Pci}) \times \Pi(1-2 / \mathrm{Pni})\right\}$

$=\operatorname{INT}\{(\mathrm{N} / 2) \times(1-1 / 2) \times \Pi((\mathrm{Pci}-1) /(\mathrm{Pci}-2)) \times \Pi(1-2 / \mathrm{Pi})\}$

$=\operatorname{INT}\left\{(\mathrm{N} / 2) \times(1-1 / 2) \times \mathrm{Kpc} \times \Pi(1-2 / \mathrm{Pi}) / \Pi(1-1 / \mathrm{Pi})^{\wedge} 2 \times \Pi(1-1 / \mathrm{Pi})^{\wedge} 2\right\}$

$=\operatorname{INT}\left\{(\mathrm{N} / 2) \times(1-1 / 2) \times \mathrm{Kpc} \times \Pi\left(1-1 /(\mathrm{Pi}-1)^{\wedge} 2\right) \times \Pi(1-1 / \mathrm{Pi})^{\wedge} 2\right\}$

$\geq \operatorname{INT}\left\{(\mathrm{N} / 2) \times(1-1 / 2) \times \mathrm{Kpc} \times \operatorname{Ctwin} \times \Pi(1-1 / \mathrm{Pi})^{\wedge} 2\right\}$

Apply the formula (6), we can obtain the formula as follows:

$\operatorname{Gp}(\mathrm{N} \mid \mathrm{N} \geq 500000) \geq \operatorname{INT}\left\{(\mathrm{N} / 2) \times(1-1 / 2) \times \mathrm{Kpc} \times \mathrm{Ctwin} \times \prod(1-1 / \mathrm{Pi})^{\wedge} 2\right\}-1$

$\geq \operatorname{INT}\left\{\mathrm{Kpc} \times\right.$ Ctwin $\left.\times N / \operatorname{Ln}(\mathrm{N})^{\wedge} 2\right\}-1 \geq \operatorname{INT}\left\{0.6601618159 \times \mathrm{N} / \operatorname{Ln}(\mathrm{N})^{\wedge} 2\right\}-1$

$\geq \operatorname{INT}\left\{0.6601618159 \times(500000) / \operatorname{Ln}(500000)^{\wedge} 2\right\}-1=\operatorname{INT}\{1916.89\}-1=1915>>1$

From above formula (8) we can obtain that:

Every even integer greater than 500000 can be expressed as a sum of two odd primes.

\section{CONCLUSION}

The Goldbach's Conjecture is a Complete Correct Theorem. Proof end.

Citation: YinYue Sha, "Every even integer greater than 500000 can be expressed as a sum of two odd primes". American Research Journal of Mathematics; V3, I1; pp:1-3.

Copyright (C) 2017 YinYue Sha, This is an open access article distributed under the Creative Commons Attribution License, which permits unrestricted use, distribution, and reproduction in any medium, provided the original work is properly cited. 